\title{
The Influence of Sludge on the Lolium Antioxidant Enzymes Activity and Malondialdehyde Content
}

\author{
Jiao Chen ${ }^{1}$, Yuanxiang Yang ${ }^{1}$, Xuemei Zhu ${ }^{1}$, Lei Wang ${ }^{1}$, Shengnan $\mathrm{Li}^{1} \&$ Pengcheng Dai ${ }^{1}$ \\ ${ }^{1}$ College of Resources and Environment, Sichuan Agricultural University, Chengdu, Sichuan, China \\ Correspondence: Yuanxiang Yang, College of Resources and Environment, Sichuan Agricultural University, 211 \\ Huimin Road, Chengdu 611130, Sichuan, China. Tel: 86-135-5182-8242. E-mail: guiluoxiang@163.com / \\ Xuemei Zhu, College of Resources and Environment, Sichuan Agricultural University, 211 Huimin Road, \\ Chengdu 611130, Sichuan, China. Tel: 86-133-0802-2243. E-mail: zhubroad@163.com
}

Received: April 26, 2012 Accepted: May 14, 2012 Online Published: July 27, 2012

doi:10.5539/jas.v4n8p253 URL: http://dx.doi.org/10.5539/jas.v4n8p253

\begin{abstract}
Using the soil of abandoned lead-zinc tailings and heavy metal enrichment plants (Lolium) as materials, through the outdoor pot experiment, study the influence of sludge on antioxidant enzymes (CAT, SOD and POD) activity and malondialdehyde (MDA) content. The results showed that: CAT activity increased with the increase of sludge concentration, increased first and then decreased, at concentration $(278 \mathrm{~g} / \mathrm{kg})$ to reach the highest: aerial parts 4.224 [u/(gFW.min)], roots 1.532 [u/(gFW.min)]; SOD and POD activity increased with increasing sludge concentration trends, high concentrations $(417 \mathrm{~g} / \mathrm{kg}$ ) reached the highest, concentration of aerial parts and root SOD were $0.2134[\mathrm{~W} /(\mathrm{h} . \mathrm{gFW})]$ and 0.1376 [W/(h.gFW)]. Aerial parts of Lolium MDA content increased with sludge concentration increased, while roots was manifested in the opposite trend.The study showed that high concentrations $(417 \mathrm{~g} / \mathrm{kg})$ sludge can significantly improve antioxidant enzyme activities of Lolium, reduce cell damage and increase their resistance to lead-zinc stress.
\end{abstract}

Keywords: sludge, Lolium, lead-zinc tailings, antioxidant enzymes, malondialdehyde

\section{Introduction}

With China's rapid economic growth, environmental problems caused by the mineral mining process is also an increasing number, especially the heavy metal pollution of soil. It was very difficult to repair once polluted by heavy metals. In addition, mine tailings soil water, protecting fertilizer performance is sent (Hao et al., 2002), the heavy metal content is extremely high, which all causes poisoning habitat to plant growth (Xia et al., 2001). Therefore, the ecological recovery is an urgent problem to be solved, but also is a hot topic of ecological restoration.

At present, the use of traditional single physical and chemical methods to repair soil heavy metal pollution costs too much, while the phytoremediation control pollution has low cost, simple technology advantage (Xiang et al., 2009; Wong, 2003). Phytoremediation means that plants can absorb fixed pollutants, but also restore soil functions and maintain vegetation continued to go far (Hernández-Allica et al., 2006; Sun et al., 2005). Among them, adding paper sludge, urban sludge, urban life waste and other organic amendments can improve the matrix toxicity and increase nutrition and promote plant growth (Bao et al., 2008; Chen et al, 2008). These can promote the surface of plant growth at the same time, avoid the food chain, the potential threat to human life, so it is a good way to use to deal with the sludge and restore the ecological environment.

Lead and zinc is one of the more important metal mineral resources in Southwest. Sichuan Province Han yuan belongs to the Da du dry hot valley, the county of plant species rich, and Zinc mine more representative of a certain $\mathrm{Zn}$ mining area in southwest Sichuan.The study results confirmed Lolium was the accumulation plant of heavy metals (Yuan et al., 2005). For the above reasons, use the soil of abandoned lead-zinc district and heavy metal enrichment plants (Lolium) as materials, through the pot experiment, to study the influence of different concentrations of sludge on antioxidant enzymes activity and malondialdehyde content, in order to find out sludge concentration that could effectively improve lead and zinc stress resistance of Lolium. Finally sludge will be applied to the lead and zinc wasteland, for repairing similar abandoned mining area as a reference. 


\section{Materials and Methods}

\subsection{Test Materials}

The plants tested: Lolium perenne (species name: ultra-high).

The tested soil: contaminated soil from the Tangjiashan Zinc mine tailing, a yellow-brown, each block took three soil samples by the diagonal, taking the surface $0-20 \mathrm{~cm}$ soil, mixing air-dried, ground $5 \mathrm{~mm}$ sieve. In this experiment, $15 \%$ of the sample parallel, the National Institute of Standards of the sample GBW07405 and reagent blank as a quality control. The basic physico-chemical characteristics of soil and content of lead and zinc of soil in Table 1, Table 2, the details of determining methods can be found in "Analysis of soil characteristics"(Bao, 1999).

Table 1. Basic physico-chemical characteristics in soil

\begin{tabular}{cccccc}
\hline $\mathrm{pH}$ & $\mathrm{OM}(\mathrm{mg} / \mathrm{kg})$ & $\mathrm{AN}(\mathrm{mg} / \mathrm{kg})$ & $\mathrm{AP}(\mathrm{mg} / \mathrm{kg})$ & $\mathrm{AK}(\mathrm{mg} / \mathrm{kg})$ & $\mathrm{OC}(\mathrm{mg} / \mathrm{kg})$ \\
\hline 7.36 & 33.78 & 91.00 & 12.73 & 32.90 & 19.59 \\
\hline
\end{tabular}

Table 2. The content of lead and zinc in soil $(\mathrm{mg} / \mathrm{kg})$

\begin{tabular}{lccccc}
\hline \multirow{2}{*}{ Mines } & \multirow{2}{*}{ Areas } & \multicolumn{2}{c}{ Lead } & \multicolumn{2}{c}{ Zinc } \\
\cline { 3 - 6 } & & Total content & Available content & Total content & Available content \\
\hline Tangjiashan & Tailings & 4281.07 & 484.33 & 1226.18 & 210.90 \\
\hline
\end{tabular}

\subsection{Test Methods}

\subsubsection{Plant Cultivation}

After the screening of soil and conditioner mixed, load diameter of $21 \mathrm{~cm}$, height $20 \mathrm{~cm}$ plastic pots, a pot of $1.5 \mathrm{~kg}$, a total installed soil 12 pots. The sludge design low (W-A), Intermediate (W-B), high (W-C) three levels (Table 3), without adding sludge as the control group (CK), each treatment set three times repeated. After placing four weeks, select a plump grain of Lolium, the pre-treatment (disinfection, after soaking, germination), Lolium seeds sow to plastic pots, and then move into natural conditions (Sichuan Agricultural University New Farm) until the Lolium seedlings are long homogeneous, each pot retains 20. For 60 days, take the whole plant experiments index measures. The design of modifier concentration in Table 3.

Table 3. The design of modifier concentration $(\mathrm{g} / \mathrm{Kg})$

\begin{tabular}{ccccc}
\hline Amendments & $(\mathrm{CK})$ & Low(W-A) & Intermediate(W-B) & High(W-C) \\
\hline sludge & 0 & 139 & 278 & 417 \\
\hline
\end{tabular}

\subsubsection{The Extraction of Enzyme Solution}

The harvest of Lolium was divided into the aerial parts and root.The sample rinsed with tap water, and then washed twice with deionized water.After sucking, take $1.0 \mathrm{~g}$ pre-cooling research, gradually add the pre-cooling the extract $10 \mathrm{~m} \mathrm{~L}$ and a small amount of quartz sand, ice bath, ground into a homogenate, low temperature $\left(4^{\circ} \mathrm{C}\right)$ $10000 \mathrm{r} / \mathrm{min}$ centrifugation for $20 \mathrm{~min}$, take the supernatant for crude extracts of enzyme, set aside low temperature preservation.

\subsubsection{Index Determination}

Determination of antioxidant enzymes: catalase (CAT) activity was measured according to the hydrogen peroxide decomposition (Gao, 2006), superoxide dismutase (SOD) activity was measured in accordance with the nitroblue tetrazolium (NBT) method ( $\mathrm{Li}, 2000$ ), peroxideactivity (POD) activity was measured with reference to the guaiacol method (Hu et al., 1997); Determination of malondialdehyde (MDA) content: the reference thiobarbituric method ( $\mathrm{Li}, 2000)$.

\subsection{Data Processing}

Data with Excel 2003 and SPSS 13.0 software in statistical analysis. 


\section{Results and Analysis}

\subsection{Effects of Slurry on CAT Activity of Lolium}

The CAT activity of Lolium aerial parts and roots growing in the lead-zinc tailings contaminated soils all increased under the sludge level of treatment, compared with the control (Figure 1). With sludge concentration increased, CAT activity of Lolium aerial parts and roots increased first and then decreased. Especially in the processing of the concentration $(278 \mathrm{~g} / \mathrm{kg})$, both CAT activity reached the maximum for the 4.224 and 1.532 $[\mathrm{u} /(\mathrm{gFW} \cdot \mathrm{min})]$ that compared with the control significantly increased by $458 \%$ and $272 \%$. These showed that the sludge concentration $(278 \mathrm{~g} / \mathrm{kg})$ can significantly improve Lolium CAT activity, which can effectively protect cell membranes against heavy metal stress injury.

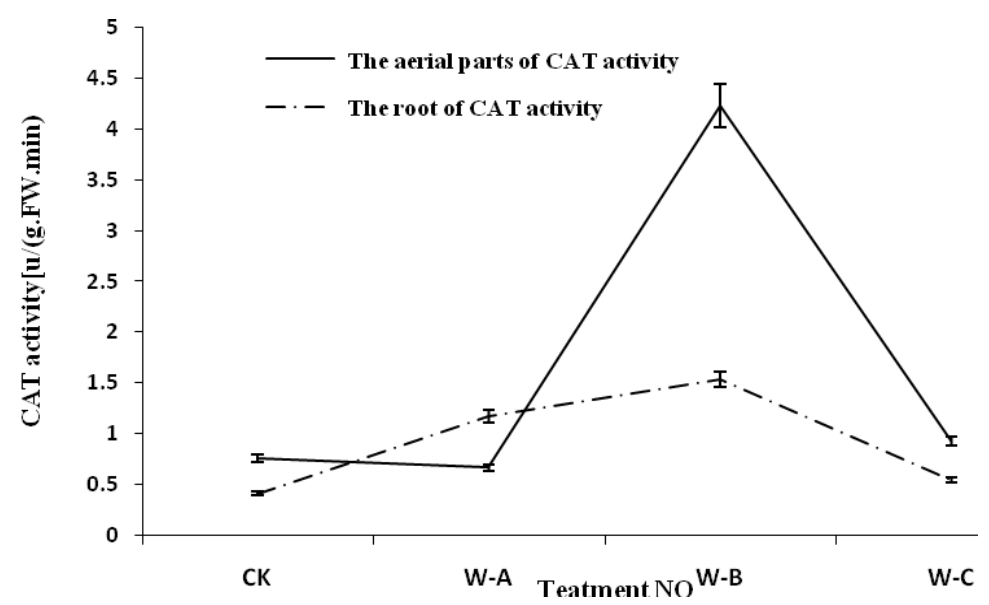

Figure 1. The relationship of CAT activity and sludge concentration

\subsection{Effects of Slurry on SOD Activity of Lolium}

The SOD activity of Lolium aerial parts and roots growing in the lead-zinc tailings contaminated soils all increased under the sludge level of treatment, compared with the control, and the various parts of the treatment than in the control reached a significant level (Figure 2). Along with the increase of slurry, Lolium aerial parts and root SOD activity overall increased. Especially in the processing of high concentration $(417 \mathrm{~g} / \mathrm{kg})$, both SOD activity reached the maximum, respectively 0.2134 and 0.1376 [W/(h.gFW)] that compared with the control significantly increased by $155 \%$ and $75 \%$. And the aerial part of the increase of SOD activity ingreater than the root. Studies have shown that the high concentration of the sludge can effectively increase the SOD activity of Lolium plants, and enhance its lead and zinc stress resistance, help to reduce the role of lipid peroxidation and membrane damage.

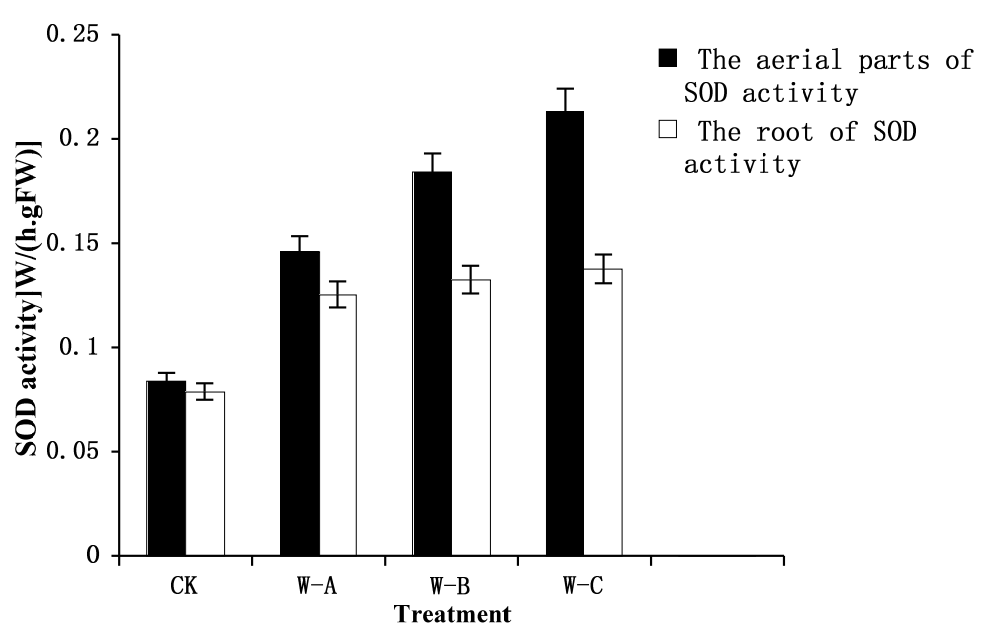

Figure 2. The relationship of SOD activity and sludge concentration 


\subsection{Effects of Slurry on POD Activity of Lolium}

The POD activity of Lolium aerial parts and roots growing in the lead-zinc tailings contaminated soils all increased in the sludge level of treatment, compared with the control, and the various parts of the treatment than in the control reached a significant level (Figure 3). With the increase of sludge concentration, the POD activity of Lolium showed an increasing trend in the overall. The aerial parts POD activity in high concentrations reached a maximum 2405 [W/h.gFW)], compared with the control significantly increased by $213 \%$; while the root POD activity in concentration $(278 \mathrm{~g} / \mathrm{kg})$ reached a maximum 2309 [W/h.gFW)], compared with the control significantly increased by $189 \%$,conditions of high concentrations of root POD activity declined slightly.The results showed that high concentration $(417 \mathrm{~g} / \mathrm{kg})$ sludge can significantly improve Lolium POD activity, improving Lolium POD activity contribute to the suppression of oxide on the membrane lipid peroxidation, thus avoiding the damage and destruction of the membrane.

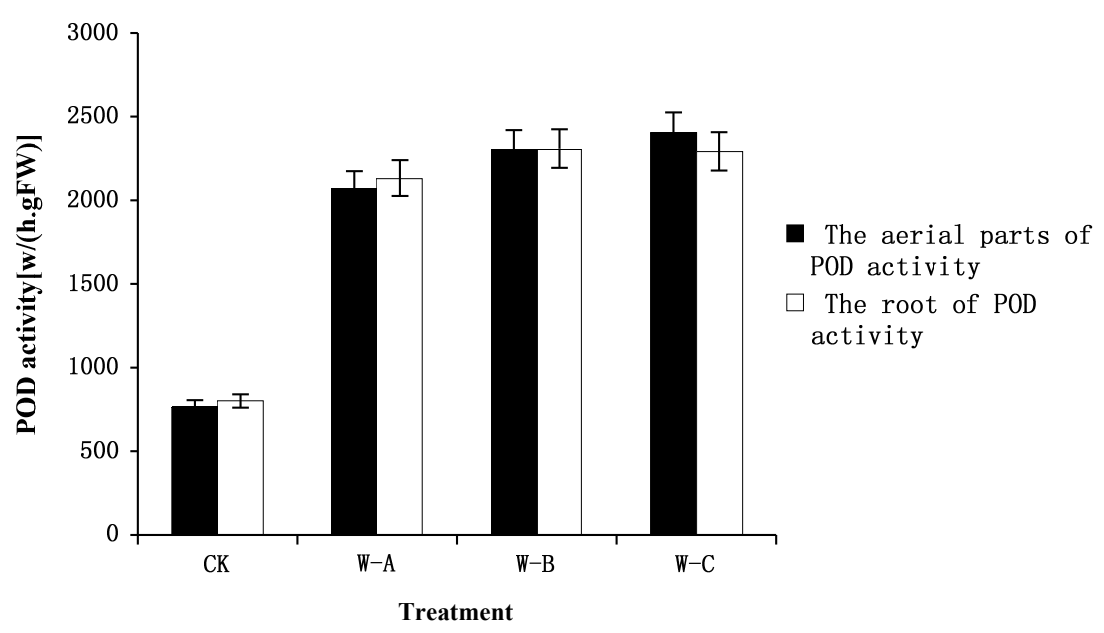

Figure 3. The relationship of POD activity and sludge concentration

\subsection{Effects of Slurry on MDA Content of Lolium}

With the sludge concentration increased, the Lolium aerial parts of MDA content showed an increasing trend (Figure 4), and reached the maximum0.059 [umol/gFW] at high concentration $(417 \mathrm{~g} / \mathrm{kg})$, increased by $32 \%$ compared with the control; Lolium root MDA content showed the opposite trend, and high concentration issued the minimum 0.037 [umol/gFW], reduced by $42 \%$ compared with the control. These showed that sludge has significant effect on Lolium aerial parts and root MDA content, which can reduce the toxic effects of root cell membranes.

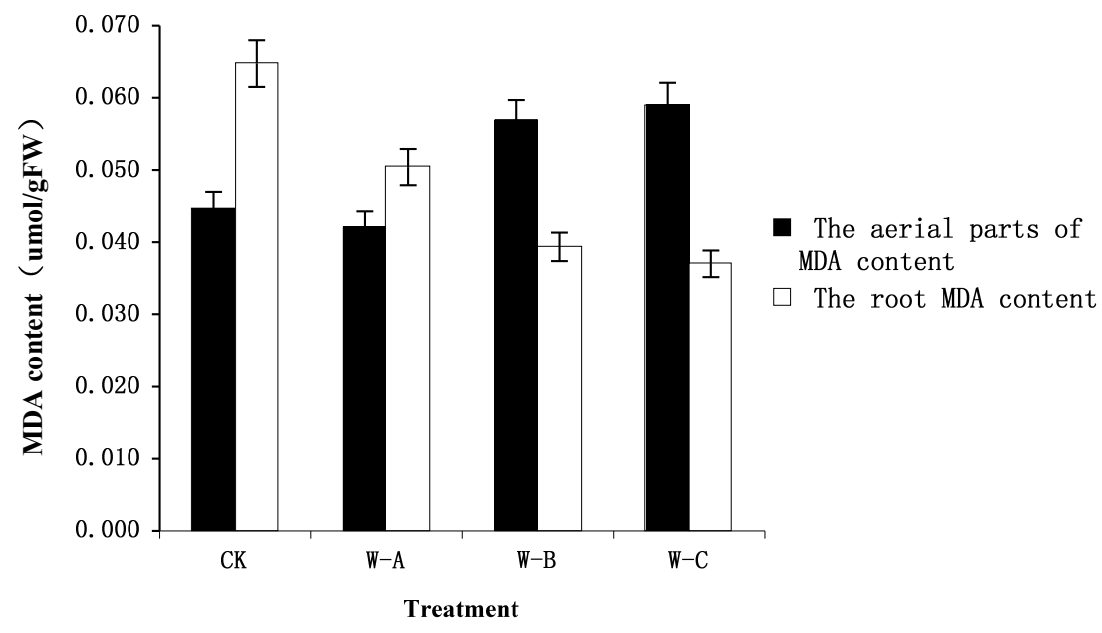

Figure 4. The relationship of MDA content and sludge concentration 


\section{Discussion and Conclusion}

1) The CAT activity of Lolium was the most obvious under the sludge concentration $(278 \mathrm{~g} / \mathrm{kg})$ that can significantly enhance the Lolium resistance to lead and zinc stress capacity under $\mathrm{Pb}-\mathrm{Zn}$ tailings.But the Lolium aerial parts of CAT activity compared with the control to reduce under sludge low concentration $(139 \mathrm{~g} / \mathrm{kg})$, indicating that the low sludge concentration $(139 \mathrm{~g} / \mathrm{kg})$ played no positive role in Lolium CAT activity. And the results was consistent with Chen ling (Chen et al., 2010). The reason may be that under the conditions of heavy metal pollution, the products of ROS increased (such as superoxide root (O-2), hydroxyl (OH-), hydroxyl radical $(\mathrm{OH})$, hydrogen peroxide $(\mathrm{H} 2 \mathrm{O} 2)$, etc), and the product increased in a very short time, causing too late to eliminate the high levels of ROS (Khatun, 2008; Stohs, 1995), thereby inhibiting the activity of CAT.

2) The Lolium SOD activity reached the highest under sludge concentration $(417 \mathrm{~g} / \mathrm{kg})$ processing, indicating that the sludge of high concentrations can significantly enhance Lolium resistance to lead and zinc stress, which was consistent with the performance of the amendments on salt and salt stress on cotton SOD activity (Chen et al., 2010). SOD as an inducible enzyme, under heavy metal stress, the reasons for the increase that $\mathrm{O}^{-2}$ content in plants increased to some extent to induce the increase of enzyme activity, while improving SOD activity can make the plant cells from poisoning (Lei et al., 2009; Yuan et al., 2005).

3) POD activity in Lolium showed the increasing trend under the sludge treatment compared with the control, this was actually a way to eliminate the manifestations of oxidative stress. With the increase of sludge concentration, the Lolium POD activity followed an upward trend, consistent with the performance of the amendments on salt and salt stress on cotton POD activity (Chen et al., 2010). The increase of POD activity may be related to the POD enzyme substrate concentration (Yan, 1997). When heavy metal ions was into the plant, the toxic substances in the plants were produced rapidly, thus increasing the POD enzyme substrate, so long as the substrate concentration within the normal decomposition ability of the POD enzyme, POD activity would be with the enzymethe increase of substrate concentration increased.

4) Lolium aerial parts of the MDA content were in the maximum under the sludge concentration $(417 \mathrm{~g} / \mathrm{kg})$ processing, which was consistent with Chen Zhi-Ming (Chen, 2010). The elevated of the MDA content was plant cell membrane lipid peroxidation level aggravate performance, membrane lipid peroxidation level aggravate eventually lead to cell membrane structural damage. While the Lolium root MDA decreased with the increase of sludge concentration, consistent with Li Chun-Xi ( $\mathrm{Li}$ et al., 2007). Therefore, the appropriate amount of conditioner amendments can make plant cell membrane oxidative damage weakened. The study showed that the sludge concentration $(417 \mathrm{~g} / \mathrm{kg})$ can significantly improve the the Lolium antioxidant enzyme activity and reduction of membrane damage, increase resistance to stress its lead and zinc. But the resistance mechanism remains to be further studied.

\section{References}

Bao, S. D. (1999). Analysis of soil characteristics. China Agriculture Press, 12.

Bao, T., Lian, M. H., et al. (2008). The Phytoremediotion of Heavy metal contaminated soils. Ecology and Environment, 17(2), 858-865.

Chen, L., Qiu, Y. F., Li, X. R., et al. (2010). Effect of soil amendment on growth traits, physiological and biochemical indices related to salt tolerance of cotton seedling under salinity stress. Journal of Northeast Agricultural Univerisity, 41(11), 22-27.

Chen, Y. Q., \& Dong, Y. H. (2008). The research and application of soil conditioner. Ecology and Environment, $17(3), 1282-1289$.

Chen, Z. M. (2010). Study on remediation of different ameliorants in heavy mental Cr contaminated soil. Taishang, Shandong Agricultural Univerisity.

Gao, J. F. (2006). The guidance of plant physiology experiments. Bei jing: Higher Education Press. 74-75, 214-215.

Hao, X. Z., Zhou, D. M., Wang, Y. J., et al. (2002). Effect of Amendments on Lolium Grown on Copper Mine Tailling. Rural Eco-Environment, 18(1), 11-15.

Hernández-Allica, L., Becerril, J. M., Zárate, O., et al. (2006). Assessment of the efficiency of a metal phytoextraction process with biological indicators of soil health. Plant and Soil, 281(1-2), 147-158. http://dx.doi.org/10.1007/s11104-005-4081-7

Hu, B., Zhu, J. M., Wu, Y. R., et al. (1997). Effect of POD on tolerance to ferrous iron toxicity in rice. Journal of Zhe jiang Agricultural University, 23(5), 557- 560. 
Khatun, S., AliM, B., Hahn, E. J., et al. (2008). Copper toxicity in Withania somnifera: growth and antioxidant enzymes responses of in vitro grown plants. Environmental and Experimental Botany, 64, 279-285. http://dx.doi.org/10.1016/j.envexpbot.2008.02.004

Lei, D. M., Duan, C. Q., \& Zhang, H. Y. (2009). Laad and zinc induced changes in activity of antioxidant enzymes of Rumex dentatus, a kind of pioneer plant growing on mine tailing. Acta Ecologica Snica, 29(10), 5417-5423.

Li, C. X., Shao, Y., Hou, X. L., et al. (2007). The influence of Ammonia fertilizer, phosphate fertilizer, fly ash and $\mathrm{CaCO}_{3}$ under As (III) stress on biological effects of wheat seedlings and mature grain As content. Environmental Sciences, 20(6), 49-55.

Li, H. S. (2000). The principles and techniques of plant physiological and biochemical experiments. Bei jing: Higher Education Press. 182-186, 134-137, 260-269.

Stohs, S. J., \& Bagchi, D. (1995). Oxidative mechanisms in the toxicity of metalions. Free Radical Biology and Medicine, 18, 321-336. http://dx.doi.org/10.1016/0891-5849(94)00159-H

Sun, Q. Y., Ren, G. J., Yang, L. Z., et al. (2005). Influence of Natural plant communities to copper tailings lands the soil enzyme activity. Acta Pedologica Sinica, 42(1), 37-43.

Wong, M. H. (2003). Ecological restoration of mine degraded soils, with emphasis on metal contaminated soils. Chemosphere, 50(6), 775-780. http://dx.doi.org/10.1016/S0045-6535(02)00232-1

Xia, H. P., Shu, Wen, S. (2001). Rrsistance to and uptake of heavy metals by Vetiveria zizanioides and paspalum notatum from lead/zinc mine tailings. Acta Ecologica Snica, 2l(7), 1121-1122.

Xiang, Y. Y., Fen, T., Liu, B. R., et al. (2009). Influence of Mn Mine Tailings Amended With Sewage On Plant Growth Of Four Ornamental Species and Accumulation of Heavy Metals. Journal of Agro-Environment Science, 28(2), 244 - 250.

Yan, Z. L., Fu, S. Z., Fang, Z. H., et al. (1997). Effect of Hg, Cd, and their common role in tobacco chlorophyll content and antioxidant enzyme systems. Journal of Plant Ecology, 21(5), 468-473.

Yuan, M., Tie, B. Q., \& Tang, M. Z. (2005). Single heavy metal pollution on the growth and physiological and biochemical characreristics of Eulaliopsis binata. Chinese Journal of Eco-Agriculture, 36(6), 929-932.

Yuan, M., Tie, B. Q., Tang, M. Z., et al. (2005). Resistance to and uptake of four grass pollution of heavy metals lead and zinc tailings. Ecology and Environment, 14(1), 43-47. 